\title{
Le Récit aujourd'hui. Arts, littérature, sous la direction de Jérôme Game
}

\section{Stefano Genetti}

\section{Q OpenEdition \\ 1 Journals}

\section{Edizione digitale}

URL: https://journals.openedition.org/studifrancesi/3232

DOI: $10.4000 /$ studifrancesi.3232

ISSN: 2421-5856

\section{Editore}

Rosenberg \& Sellier

\section{Edizione cartacea}

Data di pubblicazione: 1 juillet 2013

Paginazione: 493

ISSN: 0039-2944

\section{Notizia bibliografica digitale}

Stefano Genetti, «Le Récit aujourd'hui. Arts, littérature, sous la direction de Jérôme Game», Studi

Francesi [Online], 170 (LVII | II) | 2013, online dal 30 novembre 2015, consultato il 02 février 2023. URL: http://journals.openedition.org/studifrancesi/3232 ; DOI: https://doi.org/10.4000/studifrancesi.3232

Questo documento è stato generato automaticamente il 2 février 2023.

\section{(c) (i) (9)}

Creative Commons - Attribuzione - Non commerciale - Non opere derivate 4.0 Internazionale - CC BYNC-ND 4.0

https://creativecommons.org/licenses/by-nc-nd/4.0/ 


\title{
Le Récit aujourd'hui. Arts, littérature, sous la direction de Jérôme Game
}

\author{
Stefano Genetti
}

\section{NOTIZIA}

Le Récit aujourd'hui. Arts, littérature, sous la direction de Jérôme GAME, Saint-Denis, Presses Universitaires de Vincennes, 2011 («Esthétiques hors cadre»), pp. 176.

1 Come sottolinea Jérôme GAME nello scritto teorico introduttivo (D'un art syntaxique, pp. 5-19), la nozione di sintassi si pone al centro di questo insieme di saggi incentrati sulle «nouvelles économies du récit et de la narration» (p. 5) che si vanno profilando nei vari campi della creazione artistica. Al di là di ogni sequenzialità teleologica e di un approccio meramente "grammaticale", linguistico e narratologico, la «créativité syntaxique» viene qui intesa, in termini sia stilistici che speculativi, come composizione di squilibri, come articolazione dinamica di «signification et intensité» (p. 17) utile a interrogare l'atto di raccontare, «c'est-à-dire de tramer des énoncés et, ce faisant, figurer un monde» (p. 6), nonché a estenderne le modalità e gli effetti anche a sistemi semiotici non verbali. A fornire la «boîte à outils conceptuels» (p. 17) di una rinnovata epistemologia del racconto sono allora pensatori quali Deleuze e Derrida, Ricœur (il racconto come sintesi dell'eterogeneo) e Rancière (la phrase-image).

2 In un'ottica aperta e plurale, programmaticamente interdisciplinare, i contributi spaziano dal cinema (Pierre SORLIN, Entre syntaxe et créativité: ordre et liberté du montage, pp. 57-71, su Bergman e Kurosawa) alle arti visive e alla performance (Joseph MOUTON, Remarques autour de la narration beuyssienne, pp. 127-136; Christine Ross, Répétition et longue durée ou la syntaxe de l'installation vidéo chez Stan Douglas, pp. 137-160, sull'opera di un video-artista canadese profondamente influenzato dall'arte combinatoria beckettiana, che associa iterazione, permutazione e contraddizione). I riferimenti letterari abbondano anche negli studi che vertono su altre pratiche artistiche. In D'une grammaire des surfaces (pp. 37-55), Éric SUCHÈrE evoca Emmanuel Hocquard 
nell'illustrare le diverse tecniche dell'attuale tendenza pittorica all'«abstraction syntaxique» (p. 44); Christian DOUMET (La Musique, comment dire, pp. 73-84) si rifà a Jean Tardieu nel trattare dell'incapacità del linguaggio a dire la musica in quanto sistema di segni che comunicano ma non significano, né rappresentano, al pari dei fraseggi disegnati nello spazio dal corpo in movimento e indagati da Véronique FABBRI in un percorso che, tra espressionismo e astrattismo coreografico, va da Laban e Valéry all'odierna filosofia del gesto (Syntaxe de la danse, pp. 85-108), mentre sui concetti di "phrase théâtrale» e di surface textuée (p. 110) come materiali ritmico-drammaturgici poggia l'analisi proposta da Éric VAUTRIN di alcune mises en scène di Claude Régy, Romeo Castellucci e François Tanguy (De la représentation théâtrale comme texture ou comment la syntaxe serait un nouvel art du discontinu, pp. 109-125).

Quasi a ribadire la centralità del confronto con la scrittura letteraria nell'interazione fra le arti, a chiudere il volume sono le considerazioni di Aliocha WALD LASOWSKI sulla barthesiana «syntaxe du fragment» (p. 164), sull'«écriture de l'incident» (p. 165) atta ad accogliere - raccogliere e introiettare - la diversità dei momenti vissuti nell'epifanico «instant "amoureux" de la phrase» (p. 166; Tempo-Barthes: quand la syntaxe saisit la pensée, pp. 161-171). Nell'articolo di apertura, intitolato Narrations documentaires: un art contemporain de la syntaxe littéraire (pp. 21-36), Lionel RUFFEL passa in rassegna vari testi di attualità: T. Vollmann (quasi un'enciclopedia sulla violenza), S. Alexievitch (su Chernobyl), J. Hatzfeld (sul Ruanda), ma anche Gomorra di Roberto Saviano e La Clôture di Jean Rolin. Memori della lezione del reportage fotografico e del film documentario, sono testi che, pur adottandone metodi e strumenti, prendono le distanze dalla tradizione narrativa realista e dall'inchiesta giornalistica. In queste opera, «l'agencement, la syntaxe de documents» provoca «simultanément un effet de document et un effet de réel» (p. 30), contribuendo a una mappatura cognitiva del mondo e a una memoria del presente cui la complessità della postura autoriale, dovuta all'inquadramento, all'assemblaggio e alla conseguente riconfigurazione e interpretazione dei documenti mobilitati, conferisce inevitabilmente valenze etiche e politiche. Nella logica dell'eterogeneità che caratterizza questa «littérature des conjonctions» (p. 30), l'A. vede il sintomo di un'estetica, eminentemente contemporanea, dell'«impureté» e dell'«impropre» (p. 22), di una nuova narratività composita, ibrida, a un tempo fluida e discontinua. 